\title{
Correction to: Open Skies: The National Radio Astronomy Observatory and Its Impact on US Radio Astronomy
}

\author{
Correction to: K. I. Kellermann et al., Open Skies, \\ Historical \& Cultural Astronomy, \\ HTTPS://DOI.ORG/10.1007/978-3-030-32345-5
}

A number of corrections were unfortunately missed during the proofing and correction process. The version supplied here has been updated.

FM page iv

In cover caption, changed from "Plains of San Agustin, 50 miles east of Socorro" to "Plains of San Agustin, 50 miles west of Socorro"

Page 39, line 14

Added diacriticals to François, Émile

Page 40, line 4 in the Japan section

Added T. Hatanaka

Page 42, paragraph 2, lines 7-8

Changed from: "On 12 February two German destroyers" to "On 12 February two German warships"

Page 47, paragraph 2, line 6

Changed "strong sources appear weaker than any given flux density level" to "strong sources appear weaker at any given flux density level"

Page 51, lines 8-9

Changed from: "Wurzburg antenna at Kootwijk on the Dutch coast, Muller and Oort." to "Wurzburg antenna at Kootwijk in central Holland, Muller and Oort."

Page 61, line 4

Changed from "inner 20 meter diameter" to "inner 20 foot diameter"

Page 63, Fig. 2.8 caption

The updated online version of the book can be found at https://doi.org/10.1007/978-3-030-32345-5

(C) The Author(s) 2021

K. I. Kellermann et al., Open Skies, Historical \& Cultural Astronomy,

https://doi.org/10.1007/978-3-030-32345-5_12 
Changed from: "Prof. Jan Oort and Mrs. Oort leaving the 1955 dedication of the Dwingeloo 25 meter radio telescope." to "Prof. Jan Oort and Queen Juliana leaving the $\mathbf{1 9 5 6}$ dedication of the Dwingeloo 25 meter radio telescope."

Page 65, line 2

Changed "Haleakula" to "Haleakela"

Page 75 Leverington, D. reference

Changed "Observations and Telescopes of Modern Times" to "Observatories and Telescopes of Modern Times"

Page 81

Changed "Berkly" to "Berkeley"

Page 103

Removed extra "a" from "an urgent a need"

Page 104, middle paragraph, last line

Removed extra "a" from "as a major a program"

Page 130, line 5

Changed from "operated with ten miles" to "operated within ten miles"

Page 168, Fig. 4.5 caption

Changed from "Dedication of the 85 Foot Howard E. Tatel Telescope, 16 October 1968."

to "Dedication of the 85 Foot Howard E. Tatel Telescope, 16 October 1958." Page 193, 6 lines from bottom

Added "the" in "...it is the largest equatorial"

Page 215, line 9

Changed from "debated the augments" to "debated the arguments"

Page 272, Fig. 6.5, last line of caption

Changed from "J. Findley" to "J. Findlay"

Page 275, 4 lines from bottom

Changed from "von Hoerner begin using" to "von Hoerner began using" Page 282, last paragraph, line 4

Changed from "The WMAP satellite contained 20 NRAO HEMT amplifiers." to "The WMAP satellite contained 80 NRAO HEMT amplifiers."

Page 288-289

Changed from "Stephen Chu, a 1970 student, went on to win a Nobel Prize in Physics and later became Secretary of the Interior in Barack Obama's administration." to "Stephen Chu, a 1970 student, went on to win a Nobel Prize in Physics and later became Secretary of Energy in Barack Obama's administration."

Page 291, line 11

Changed from "known as VRO 46.26.01" to "known as VRO 42.22.01"

Page 291, line 3 of $U$ Mich section

Added "to" in "used to locate Japanese ships"

Page 297, paragraph 2, line 10

Changed from "a large track of land" to "a large tract of land"

Page 306, 8 lines from end 
Changed from "Instead it he sent it back with the terse note" to "Instead, he sent it back with the terse note"

Page 307, line 10

Deleted extra "that" from "large that that the atmosphere"

Page 340, line 6

Changed from "visiting from Sweden in 1967" to "visiting from Holland in 1967"

Page 396, line 10

Changed from "August 1967 URSI General Assembly held in Montreal." to "August 1967 URSI Radio Science Meeting held in Montreal"

Page 462, middle paragraph, 2 lines from end

Changed from "it would take a freak 1989 accident" to "it would take a freak 1988 accident."

Page 480, 2 lines from bottom

Changed from "von Hoerner commented that LSFT" to "von Hoerner commented that LFST"

Page 507, Fig. 9.12

Changed caption from "100 meter telescope concepts. Right: axially symmetrical design; Left: offset reflector 100 design." to "100-meter telescope design concepts. Left: axially symmetrical design; Right: off-set reflector design."

Page 566, 7 lines from bottom

Changed from "the primary criteria" to "the primary criterion"

Page 571, fig. 10.9

Changed caption from “.... Fred Lo (NRAO Director), Bob Brown (NRAO), Catherine Cesarsky (ESO Director General) and Daniel Hofstadt (ESO).” to “... Fred Lo (NRAO Director), Massimo Tarenghi (ESO), Catherine Cesarsky..."

Page 601, bottom line

Added "of" in the line "Most of the world's major radio telescopes"

Page 640, index entry for Jansky, Curtis Moreau

Changed from "Jansky, Curtis Moreau" to "Jansky, Cyril Moreau" 
Open Access This chapter is licensed under the terms of the Creative Commons Attribution 4.0 International License (http://creativecommons.org/licenses/ by/4.0/), which permits use, sharing, adaptation, distribution and reproduction in any medium or format, as long as you give appropriate credit to the original author(s) and the source, provide a link to the Creative Commons license and indicate if changes were made.

The images or other third party material in this chapter are included in the chapter's Creative Commons license, unless indicated otherwise in a credit line to the material. If material is not included in the chapter's Creative Commons license and your intended use is not permitted by statutory regulation or exceeds the permitted use, you will need to obtain permission directly from the copyright holder. 